\title{
Outcomes and Characteristics of Faculty/Student Mentorship in PhD Programs
}

\author{
Michelle Mollica ${ }^{1,2, *}$, Lynne Nemeth ${ }^{1}$ \\ ${ }^{1}$ College of Nursing, Medical University of South Carolina \\ ${ }^{2}$ D’Youville College, Buffalo, NY \\ *Corresponding author: mollicam@musc.edu
}

Received July 02, 2014; Revised August 12, 2014; Accepted August 15, 2014

\begin{abstract}
With increasing numbers of doctoral programs, and a persistent high attrition rate, the need to provide support to PhD students grows. Faculty mentoring is one strategy employed by many doctoral programs to address attrition, although objectives, methods and responsibilities of the mentor role vary. The purpose of this integrative literature review was to synthesize outcomes and characteristics of faculty/student mentorship in PhD programs. This integrative review included studies from 2003-April 2014 in peer-reviewed journals, found from a comprehensive search of PubMed, CINAHL, Cochrane, PsycInfo, and GoogleScholar. Key search terms included: mentor, faculty, student, advisor, doctoral, education, engagement, attrition, retention, and $\mathrm{PhD}$. The search strategy yielded a total of 850 references; 47 were retrieved, read and rated for relevance and research quality. A set of 12 articles met relevance criteria. Results indicate that although successful faculty mentoring is time consuming, students benefit from decreases in social isolation, and increased progression and retention through doctoral programs.
\end{abstract}

Keywords: mentor, doctoral programs, phd, faculty, student

Cite This Article: Michelle Mollica, and Lynne Nemeth, “Outcomes and Characteristics of Faculty/Student Mentorship in PhD Programs.” American Journal of Educational Research, vol. 2, no. 9 (2014): 703-708. doi: 10.12691/education-2-9-1.

\section{Introduction}

While the number of students enrolled in doctoral degree programs in the United States (U.S.) continues to grow, attrition rates of students average between $40-50 \%$ [1]. Factors contributing to the attrition of students includes financial, academic, and person reasons [2]. In a qualitative study of departed students of a doctoral program, students reported personal issues, departmental issues, and that they were a wrong fit for the program or institution [2]. Personal issues include marriage, children, or family responsibilities. Students described departmental issues including misadvising, lack of financial support, feelings of isolation, faculty attrition, and departmental politics. Research has demonstrated, however, the need for strategies to retain students and create research scientists and faculty for the next generation $[3,4]$. Heading the list of major factors graduates contribute to doctoral completion were financial support, family support, and mentoring/advising. While there are many variables that can promote or impede a student's progression, mentoring and advising is one strategy that doctoral programs are utilizing to support and facilitate student success [1]. The purpose of this integrative literature review is to explore and synthesize the outcomes and characteristics of studies exploring faculty-student mentoring in doctoral programs in the U.S.

\subsection{Mentor: Definition}

A mentor is a general term for an extra-familial adult that is beneficial to one's academic, professional, or personal development [5]. Specific to doctoral programs, a mentor can be the student's academic advisor, or can be someone within the institution or field of expertise. Faculty members as mentors can have tremendous influence to enhance the likelihood of success for the student by providing structure, support and guidance. For the purpose of this integrative review, a mentor will be operationally defined as a faculty mentor and/or advisor, who provides support to the student throughout the doctoral degree program to promote development as a future professional researcher [6].

\section{The Review}

\subsection{Aim}

While mentoring in doctoral education is a concept that has been studied extensively, outcomes and findings have varied drastically [4,6]. There is a gap in the literature specifically exploring the outcomes and characteristics of doctoral faculty-student mentor relationships [7]. This integrative literature review synthesizesthese outcomes and characteristics, to provide direction for future research and educational implications. The researcher will answer 
the question, What are the outcomes of, and characteristics of faculty/student mentorship in PhD programs?

\subsection{Design}

We chose an integrative literature review to identify and synthesize salient outcomes and characteristics utilized in selected prior studies. This rigorous review process enables analysis and synthesis of published quantitative and qualitative studies, and systematic reviews of the selected phenomenon [8]. Utilizing the systematic process of Whittemore and Knafl, scientists can outline the state of the science for a respective issue and contribute to policy, practice, and future research.

\subsection{Search Methods}

The search strategy included literature from 2004-2014 from PubMed, Cochrane, CINAHL, PsycINFO, and Google Scholar. Internet searches were also conducted for statistical data, including the Council of Graduate Studies. A review of reference lists, cross searching, and journal hand searching also yielded additional items for review of inclusion criteria. The following search terms were used in combination: Mentor, faculty, student, advisor, doctoral, education, engagement, attrition, retention, and $\mathrm{PhD}$. Inclusion criteria included (a) studiesexploring facultystudent mentor relationships in doctoral ( $\mathrm{PhD}$ programs) in the U.S., (b) were peer reviewed articles published in English, and (c) were either qualitative, quantitative, or systematic reviews. Studies were excluded if they reported on the mentoring of undergraduate students, clinical or professional mentoring outside of doctoral programs, student-student mentoring, mentoring of staff or new faculty, or were dissertations, book chapters, abstracts, or presentations.

\subsection{Search Outcome}

The search strategy yielded a total of 850 references, of which 22 were duplicates. All abstracts were reviewed for relevance, excluding 782 articles. Fourty-seven articles were retrieved for further analysis, read, and reviewed. All articles were assessed for inclusion and exclusion criteria and rerated for relevance. The final set contained 13 research studies. Figure 1 represents a flowchart for article selection.

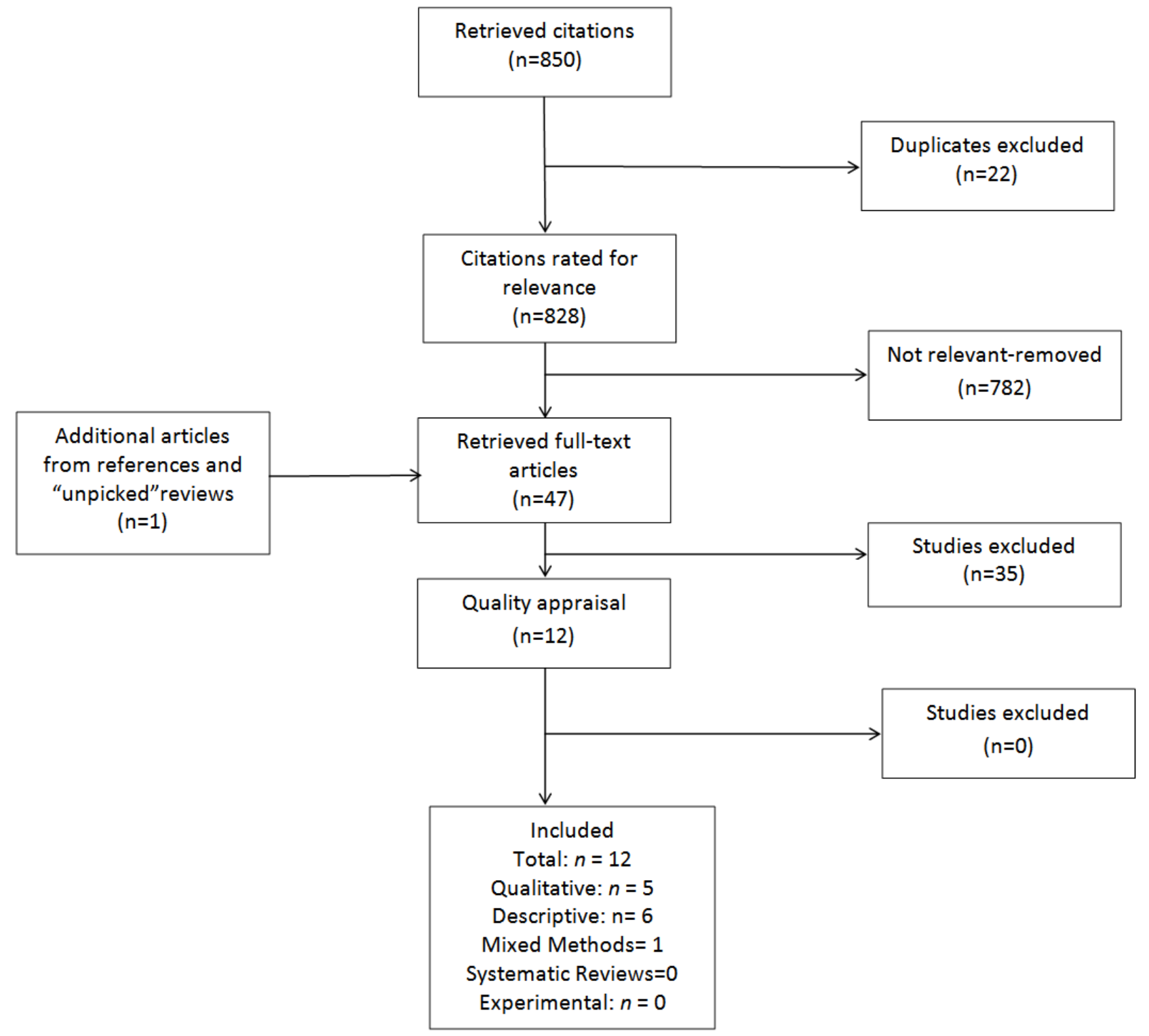

Figure 1. Flowchart for article relevance assessment 


\subsection{Data Abstraction}

Data were abstracted from each selected article based on the following considerations: purpose of study, design, data collection instruments, sample demographics, size, and analysis. Specific attention was given to the factors and characteristics of faculty-student mentor relationships in each research study, which are synthesized in the Results section of this integrative review.

\subsection{Quality Appraisal and Synthesis}

Studies were divided into study design (qualitative, quantitative experimental, quantitative descriptive, mixed methods, and systematic review, where appropriate), and individually evaluated and appraised using the appropriate evaluation tools for each study design. Descriptive quantitative studies were evaluated with the Strengthening the Reporting of Observational Studies (STROBE) tool
[9], quantitative experimentation studies assessed with the Consolidated Standards of Reporting Trials (CONSORT) tool [10], and qualitative studies were appraised with the Critical Appraisal Skills Program [11]. It is important to note that no study was excluded based on evaluated data, however the variance in meeting criteria was included as a potential limitation and variable, per Whittemore and Knafl[8], because less rigorous studies contribute less to the analytic process of the review. An expert researcher confirmed the quality of selected studies and concurred in deletion of excluded studies.

\section{Results}

The final set of relevant studies totaled 12, with pertinent details displayed in Table 1.

Table 1.

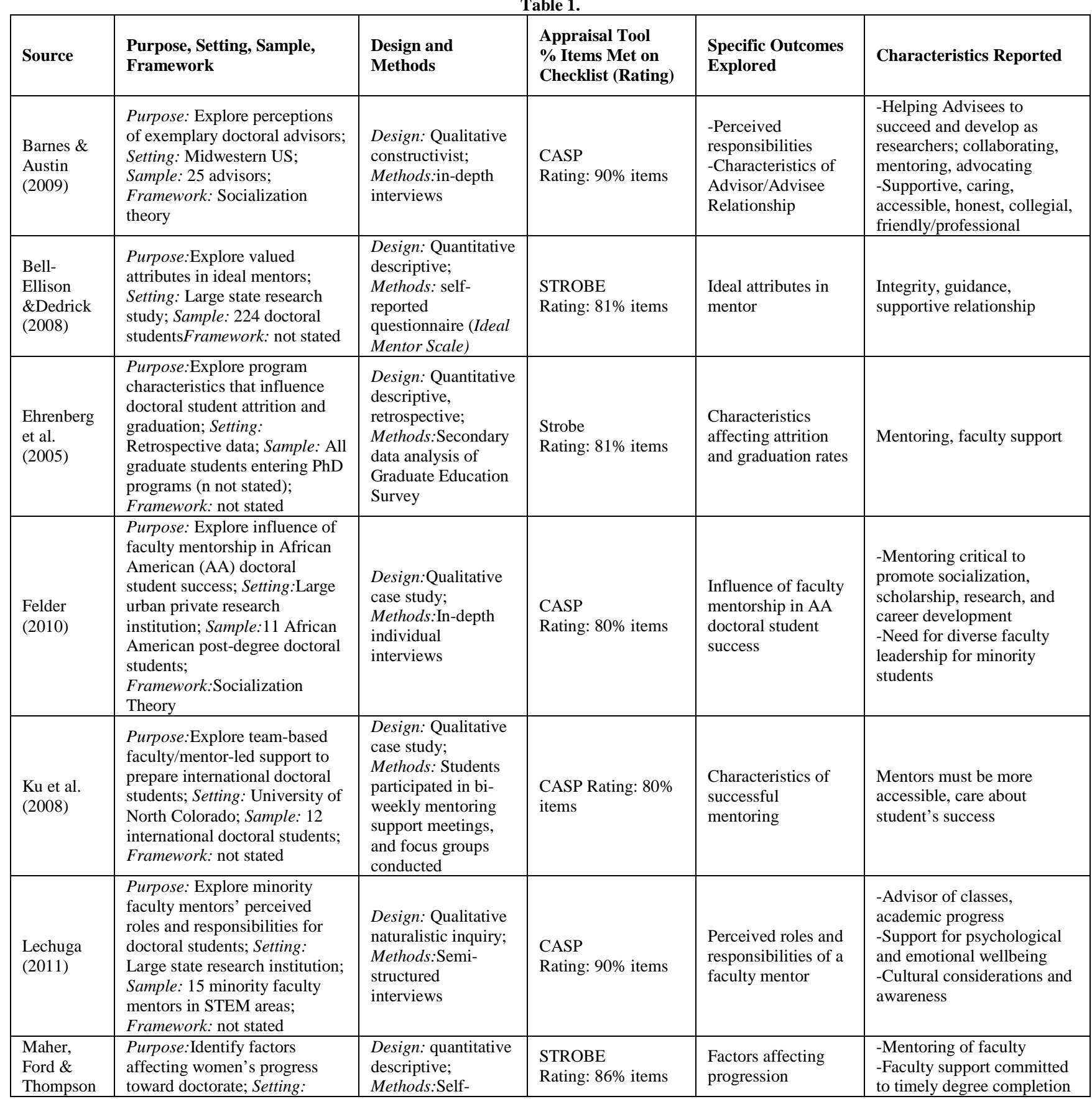




\begin{tabular}{|c|c|c|c|c|c|}
\hline (2004) & $\begin{array}{l}\text { Stanford; Sample: } 160 \text { doctoral } \\
\text { program alumni; Framework: } \\
\text { not stated }\end{array}$ & $\begin{array}{l}\text { reported survey } \\
\text { questionnaire }\end{array}$ & & & $\begin{array}{l}\text {-Mentor/advisor serves as } \\
\text { role model and pushes } \\
\text { students to succeed }\end{array}$ \\
\hline $\begin{array}{l}\text { Mullen } \\
\text { (2003) }\end{array}$ & $\begin{array}{l}\text { Purpose: Explore process and } \\
\text { outcomes of mentorship on a } \\
\text { doctoral cohort; } \\
\text { Setting:Southeastern university } \\
\text { in US; Sample: } 15 \text { cohort } \\
\text { doctoral students; Framework: } \\
\text { Not clearly stated }\end{array}$ & $\begin{array}{l}\text { Design: Mixed- } \\
\text { methods descriptive; } \\
\text { Methods:survey } \\
\text { questionnaires and } \\
\text { semi-structured } \\
\text { interviews }\end{array}$ & $\begin{array}{l}\text { STROBE and CASP } \\
\text { Rating: } 91 \% \text { items } \\
\text { on STROBE } \\
\text { 90\% items on CASP }\end{array}$ & $\begin{array}{l}\text { Outcomes of } \\
\text { mentorship }\end{array}$ & $\begin{array}{l}\text {-Developing sense of } \\
\text { identity and belonging } \\
\text {-Support for learning and } \\
\text { attaining goals } \\
\text {-Cooperative learning } \\
\text {-Decreased isolation }\end{array}$ \\
\hline $\begin{array}{l}\text { Paglis, } \\
\text { Green \& } \\
\text { Bauer } \\
(2006)\end{array}$ & $\begin{array}{l}\text { Purpose: Explore impact of } \\
\text { doctoral advisor mentoring on } \\
\text { student outcomes; Setting: } \\
\text { Midwest research institution } \\
\text { Sample: } 130 \text { doctoral and past- } \\
\text { doctoral students; Framework: } \\
\text { Kram's Mentorship Framework } \\
\text { (Kram, 1983) }\end{array}$ & $\begin{array}{l}\text { Design: quantitative } \\
\text { longitudinal } \\
\text { descriptive; } \\
\text { Methods: Entering } \\
\text { doctoral students } \\
\text { sent likert surveys, } \\
\text { and then repeated } \\
\text { during second } \\
\text { academic year, and } \\
51 \text { 1² years post } \\
\text { beginning program }\end{array}$ & $\begin{array}{l}\text { STROBE } \\
\text { Rating: } 90 \% \text { items }\end{array}$ & $\begin{array}{l}\text { Effect of mentorship } \\
\text { on research } \\
\text { productivity, career } \\
\text { commitment and } \\
\text { self-efficacy }\end{array}$ & $\begin{array}{l}\text {-Advisor's collaborative } \\
\text { mentoring predicted protégés } \\
\text { research productivity } \\
\text {-Psychosocial mentoring } \\
\text { positively influenced } \\
\text { subsequent research self- } \\
\text { efficacy } \\
\text {-No support found for the } \\
\text { proposed influence of } \\
\text { mentoring on students' later } \\
\text { career committment }\end{array}$ \\
\hline $\begin{array}{l}\text { Protivnak\& } \\
\text { Foss } \\
\text { (2009) }\end{array}$ & $\begin{array}{l}\text { Purpose: Explore themes that } \\
\text { counselor doctoral students } \\
\text { perceive influence experience; } \\
\text { Setting: US Sample: } 141 \\
\text { counselor education doctoral } \\
\text { students from accredited } \\
\text { program; Framework: not } \\
\text { stated }\end{array}$ & $\begin{array}{l}\text { Design: qualitative } \\
\text { descriptive; } \\
\text { Methods: Internet- } \\
\text { based open-ended } \\
\text { questionnaire }\end{array}$ & $\begin{array}{l}\text { CASP } \\
\text { Rating: } 80 \% \text { items }\end{array}$ & $\begin{array}{l}\text { Perceptions of } \\
\text { doctoral students } \\
\text { that influence } \\
\text { experience }\end{array}$ & $\begin{array}{l}\text {-Mentoring is affected by } \\
\text { departmental culture } \\
\text {-Mentors provide structure, } \\
\text { support, opportunities, and } \\
\text { advisement } \\
\text {-Mentoring decreases } \\
\text { isolation }\end{array}$ \\
\hline $\begin{array}{l}\text { Rose } \\
(2005)\end{array}$ & $\begin{array}{l}\text { Purpose: Examine relationship } \\
\text { between demographic and } \\
\text { academic characteristics and } \\
\text { preferences for mentoring } \\
\text { style; Setting: Two Midwestern } \\
\text { research universities; Sample: } \\
537 \text { doctoral students; } \\
\text { Framework: not stated } \\
\end{array}$ & $\begin{array}{l}\text { Design: quantitative } \\
\text { descriptive; } \\
\text { Methods: Self- } \\
\text { reported } \\
\text { questionnaire (Ideal } \\
\text { Mentor Scale) }\end{array}$ & $\begin{array}{l}\text { STROBE Rating: } \\
81 \% \text { items }\end{array}$ & $\begin{array}{l}\text { Relationship } \\
\text { between age, } \\
\text { gender, citizenship, } \\
\text { academic discipline, } \\
\text { and stage of } \\
\text { persistence, and } \\
\text { preferences for } \\
\text { mentoring style }\end{array}$ & $\begin{array}{l}\text {-Individual differences in } \\
\text { preferred mentoring style } \\
\text {-As age increased, } \\
\text { importance of personal } \\
\text { relationship aspect of } \\
\text { mentoring decreased } \\
\text {-Female students valued } \\
\text { integrity of mentor }\end{array}$ \\
\hline
\end{tabular}

\subsection{Overview of Studies}

The set includes 5 qualitative studies [12,13,14,15,16], 6 quantitative descriptive studies [4,7,17,18,19,20], and 1 mixed methods study [21]. There were no quantitative experimental studies or systematic reviews appropriate for inclusion based on specified criteria. Qualitative studies utilized constructivist, naturalistic, case study, and descriptive methodologies. All quantitative descriptive studies called their designs exploratory or descriptive. The mixed methods study was descriptive in both quantitative and qualitative arms.

Theoretical frameworks were utilized in only 3 of the 12 studies [4,12,13,]. The theoretical frameworks were as follows: Socialization Theory [12,13], and Kram's Mentorship Framework [4].

\subsection{Outcomes and Characteristics of Mentorship}

\subsubsection{Role of the Faculty Mentor}

Four of the twelve included studies explored the role of the faculty mentor in a doctoral program [12,15,17,21]. Within the role, researchers looked at perceived responsibilities and the definition of the role of mentor, as well as boundaries and limits of the faculty mentor. Barnes and Austin [12] found that mentors help advisees to succeed and develop as researchers. They have a role in collaborating, mentoring, and advocating for the student. Mentors must also follow academic progress and provide support for psychological and emotional wellbeing of the student [15]. In addition, it is the responsibility of the mentors to have a cultural awareness of each individual student and their subsequent needs throughout the stresses of the doctoral program.

\subsubsection{Characteristics of a Successful Mentor}

Four of the twelve studies assessed the characteristics of successful mentorship [12,14,17,20]. Researchers examined the preference of students towards different mentoring styles, perceptions of mentors that can influence relationships, and factors contributing to a positive relationship. An ideal mentor should have integrity, and be supportive, caring, accessible, honest, and collegial [12,17]. Analysis of these studies indicated that students were not looking for someone to be their "friend", but rather to push them and challenge them to grow academically and professionally. Webb and colleagues [20] did find some issues with the mentoring 
process; namely that there are varying means of selecting faculty mentors and the relationship is time-consuming for faculty. Mentoring is also self-limiting by students, who must be pro-active in utilizing their mentor as a resource.

\subsubsection{Effects of a Successful Mentorship}

Five of the included studies examined the effect of a successful student-faculty mentor relationship [4,13,14,19,20,21]. Among these studies, outcomes included perceived benefits of having an effective faculty mentor, the influence of mentorship on academic success, and the effect of mentorship on research productivity, career commitment and self-efficacy. Results indicated that mentoring was critical to promote socialization, scholarship, research, and career development [13,14,21]. Paglis and colleagues [4] found that the collaborative mentoring with a faculty advisor predicted students' research productivity. In addition, having a mentor who provided psychosocial support through stressful situations positively influenced research self-efficacy in this longitudinal study. An effective faculty mentor was also shown to provide structure, guidance, professional opportunities, and advisement for coursework [16].

\subsubsection{Mentoring as Part of Larger Study}

Finally, two included studies explored mentoring as a component of a larger study focusing on attrition and student success $[7,18]$. Mentoring and faculty support was found to be a key indicator to reducing attrition and promoting graduation potential in doctoral students [7]. In addition, the progression of doctoral students through the program is greatly increased with successful mentoring. When faculty are committed to timely degree completion, the mentor can serve as the role model to push students to succeed [18].

\section{Discussion}

The following discussion highlights strengths and weaknesses of the current investigation that may influence future research. Table 2 provides the author's interpretation of priority factors for future research.

Table 2. Author's Interpretation of Priority Factors for Future Research

\begin{tabular}{|l|l|}
\hline Outcome Area & Future Research Priorities \\
\hline Role of faculty mentor & $\begin{array}{l}\text { Mentor versus advisor } \\
\text { Clearly delineated guidelines and boundaries }\end{array}$ \\
\hline Characteristics of a successful mentor & $\begin{array}{l}\text { Programs to support faculty mentors } \\
\text { Including mentorship education in new faculty orientation }\end{array}$ \\
\hline Effects of a successful mentorship & $\begin{array}{l}\text { Retention rate with mentorship } \\
\text { Comparing formal versus informal mentoring }\end{array}$ \\
\hline
\end{tabular}

\subsection{Role of the Faculty Mentor}

Results indicated that the role and responsibilities of a faculty mentor vary greatly among institutions, and even within departments [12], and range from very formal (meeting twice weekly) to informal (on an as-needed basis). Personality differences can also play a role in the level of involvement that faculty choose to have as they mentor a doctoral student. The research is clear that the faculty mentor has a responsibility to help mentees to succeed and develop as researchers and future professionals, and that this can include collaborating, mentoring, and advocating. Institutions and doctoral programs should set a clear expectation of faculty about mentoring, including responsibilities, boundaries, and expectations. It is clear that there is not a "one size fits all” type of mentorship for all doctoral students, but general guidelines for the role should be delineated. Future research should focus on the effect of a standardized mentor program on the success and retention of doctoral students.

\subsection{Characteristics of a Successful Mentor}

This review found that although students have different preferences for mentoring style, there are several components to a successful mentor. Accessibility of the mentor was the most often cited characteristic among these studies $[12,14,15,17]$. Students want to work with a faculty mentor that can facilitate their progress. They also want a mentor who will challenge them academically and professionally, while supporting and advocating for them. It is important to note that the doctoral process is a time where critiques and critical feedback are the norm, and students in these studies did not seek a mentor to be their friend [16]. Students sought mentors who aided in their academic growth.

\subsection{Effect of a Successful Mentorship}

Several studies indicated the importance of a successful mentorship on retention of doctoral students [13,18], but students who experienced successful mentorship also reported decreased isolation within their doctoral program $[21,16]$. Students in traditional doctoral programs face many challenges with keeping the balance between life and graduate studies, and mentors can support the students in stressful times. In addition, with increasing numbers of online doctoral programs, there will be a need for stronger mentorship to keep the doctoral student connected to the process.

\subsection{Future Research}

Although mentorship is included as a componentto address attrition concerns in doctoral programs, more research is warranted. Studies should focus on the differences between a formal and informal mentoring program. In addition, the difference between advisor and mentor, if any, was not addressed in the included work, and appeared to be used interchangeably. Future research could explore the role of the advisor, and if this includes supportive mentoring, or only class selection and program facilitation. Faculty also cited some challenges to being an effective mentor, including time. Studies are warranted that examine these issues, and the implementation of strategies to support faculty as well as students. 


\subsection{Limitations}

Despite the rigor of the process, important work regarding the mentorship in doctoral education may not have been included in this research for several reasons. Based on exclusion and inclusion limitations, pertinent studies that did not identify the specified key words may have been missed. As a result of the sampling method, some research concerning mentorship outcomes and characteristics may have been excluded. Although an attempt was made to capture adequate representation by different disciplines, inadvertent exclusion of important work may have occurred during the screening of papers. As a result, it is possible that relevant information might have been missed. In addition, limiting articles to those published in the English language could also have resulted in the exclusion of important work.

\subsection{Conclusions and Implications for Doctoral Education}

Results from this integrative review indicate that successful faculty mentoring in a doctoral program can have a positive effect on student growth, attrition rates, research productivity, and career development. Instituting a formal faculty mentorship program could address issues of isolation and stress during this challenging educational time. As the number of traditional and online doctoral programs grow, it will become even more imperative to support and advocate for graduate students to facilitate completion and professional success.

\section{Acknowledgements}

Ms. Mollica has received support from the American Cancer Society Doctoral Degree Scholarship in Cancer Nursing.

\section{Conflicts of Interest}

The authors have no competing interests.

\section{References}

[1] Gonzales L, Allum J, Sowell R. Graduate enrollment and degrees: 2002 to 2012. Washington, DC: Council of Graduate Schools; 2013.
[2] Gardner S. Student and faculty attributions of attrition in high and low-completing doctoral programs in the United States. Higher Education. 2008.

[3] Gardner S. Fitting the mold of graduate school: A qualitative study of socialization in doctoral education. Innovative Higher Education. 2008;33:125-38.

[4] Paglis L, Green S, Bauer T. Does adviser mentoring add value? A longitudinal study of mentoring and doctoral student outcomes. Research in Higher Education. 2006; 47(4): 451-76.

[5] Bernier A, Larose S, Soucy N. Academic mentoring in college: The interactive role of student's and mentor's interpersonal dispositions. Research in Higher Education. 2005; 46(1): 29-51.

[6] Hall L, Burns L. Identity development and mentoring in doctoral education. Harvard Educational Review. 2009; 79(1): 49-70.

[7] Ehrenberg R, Jakubson G, Groen J, So E, Price J. Inside the black box of doctoral education: What program characteristics influence doctoral students' attrition and graduation probabilities? Cornell University Working Papers. 2005; 83.

[8] Whittemore R, Knafl K. The integrative review: Updated methodology. Journal of Advanced Nursing. 2005; 52: 546-53.

[9] Gallo V, Egger M, McCormack V, Farmer P, Ioannidis JP, KirschVolders $\mathrm{M}$ et al. Strengthening the reporting of observational studies in epidemiology: An extension of the STROBE statement. PLoS Medicine. 2011; 8(10).

[10] Schulz K, Altman D, Moher D. CONSORT 2010 Statement: updated guidelines for reporting parallel group randomised trials. Annals of Internal Medicine. 2010; 152.

[11] National CASP Collaboration for Qualitative Methodologies, editor. Critical Appraisal Skills Programme (CASP). England: Public Health Resource Unit; 2006.

[12] Barnes B, Austin A. The role of doctoral advisors: A look at advising from the advisor's perspective. Innovative Higher Education. 2009; 33: 297-315.

[13] Felder P. On doctoral student development: Exploring faculty mentoring in the shaping of African American doctoral student success. The Qualitative Report. 2010; 15(2): 455-74.

[14] Ku H, Lahman M, Yeh H, Cheng Y. Into the academy: Preparing and mentoring international doctoral students. Education Tech Research Development. 2008; 56: 365-77.

[15] Lechuga V. Faculty-graduate student mentoring relationships: Mentors' perceived roles and responsibilities. Higher Education. 2011; 62: 757-71.

[16] Protivnak J, Foss L. An exploration of themes that influence the counselor education doctoral student experience. Counselor Education and Supervision. 2009; 48: 239-56.

[17] Bell-Ellison B, Dedrick R. What do doctoral students value in their ideal mentor? Research in Higher Education. 2008; 49: 55567.

[18] Maher M, Ford M, Thompson C. Degree progress of women doctoral students: Factors that constrain, facilitate, differentiate. The Review of Higher Education. 2004; 27(3): 385-408.

[19] Rose G. Group differences in graduate students' concepts of the ideal mentor. Research in Higher Education. 2005; 46(1): 53-80.

[20] Webb A, Wangmo T, Ewen H, Teaster P, Hatch L. Peer and faculty mentoring for students pursuing a $\mathrm{PhD}$ in gerontology. Educational Gerontology. 2009; 35: 1089-106.

[21] Mullen C. The WIT cohort: A case study of informal doctoral mentoring. Journal of Further and Higher Education. 2003; 27(4): 411-26. 